\title{
Quantitative competitive reverse transcription polymerase chain reaction is not a useful method for quantification of CD4 and CD8 cell status during HIV infection
}

\author{
Heather B Jaspan1, H Richard Gaumer ${ }^{2}$ and Robert F Garry*1,3
}

\begin{abstract}
Address: ${ }^{1}$ Interdisciplinary Program in Molecular and Cellular Biology Tulane University School of Medicine New Orleans LA, 70112, USA, ${ }^{2}$ Department of Pathology Louisiana State University Medical Center New Orleans LA, 70112, USA and ${ }^{3}$ Department of Microbiology and Immunology Tulane University School of Medicine New Orleans LA, 70112, USA

Email: Heather B Jaspan - hjaspan@fhcrc.org; H Richard Gaumer - hgaume@lsuhsc.edu; Robert F Garry* - rfgarry@tulane.edu

* Corresponding author
\end{abstract}

Published: 12 March 2003

Journal of Negative Results in BioMedicine 2003, 2:2

This article is available from: http://www.jnrbm.com/content/2/I/2

(c) 2003 Jaspan et al; licensee BioMed Central Ltd. This is an Open Access article: verbatim copying and redistribution of this article are permitted in all media for any purpose, provided this notice is preserved along with the article's original URL.

\begin{abstract}
Background: A polymerase chain reaction (PCR)-based method for quantitating CD4 and CD8 mRNA could provide a means of assessing immune status of AIDS patients and other immunologically compromised persons without requiring large blood draws, and could be exquisitely sensitive. Such a method would also be useful in assessing the immune status of patients retrospectively.
\end{abstract}

Results: Quantitative competitive reverse transcription PCR (QC-RT-PCR) assays were developed for measurement of CD4 and CD8 mRNA. Samples were obtained from HIV-positive and negative patients whose CD4 and CD8 counts had been determined via Flow Cytometry. The quantity of CD4 $(n=13)$ and CD8 $(n=28)$ mRNA standardized according to GAPDH mRNA quantities, all determined by QC-RT-PCR, were compared to cell number as determined by flow cytometry. There was no correlation between CD4 and CD8 cell counts and mRNA levels of CD4 and CD8 as determined by QC-RT-PCR. There is no correlation between CD4 and CD8 mRNA levels and the number of cells expressing these proteins on their surface.

Conclusion: QC-RT-PCR, and related methodologies are not useful substitutes for assessment of CD4 and CD8 cell numbers in HIV-infected persons.

\section{Background}

The progression of HIV disease involves various stages characterized by changes in lymphocyte subsets and viral load. After initial infection, an acute viremic stage occurs, which is accompanied by a rapid decline in the number of CD4+ T lymphocytes and a slow increase in CD8 counts. During the clinical latency phase, CD4 counts gradually decline, and HIV load is lower than during the acute stage, although virus is still present [1]. Finally, the late stage of HIV disease is reached, where CD4+ T-cells fall severely, and the number of viral particles surge. In the case of the HIV infected patient, emphasis is placed on CD4 counts because when the number of CD4+ T-cells falls below a critical level, prophylaxis against opportunistic infection is initiated.

Flow cytometry is not useful for samples that have been frozen or stored, therefore retrospective studies involving HIV-infected patients' samples are unable to view the data in the light of information regarding the immune status at 
the time the samples were frozen. We also perceived that studies of HIV-1 status, particularly in infants, could be facilitated by a technique using smaller amounts of blood, such as that from a heelstick or finger-prick [2]. Quantitative methods for reverse transcriptase polymerase chain reaction (RT-PCR) are rapidly surpassing all other methods of quantifying mRNA levels. We therefore set out to develop an RT-PCR based method to quantitate CD4 and CD8 mRNA in the hopes that this could be used to predict cell counts. Although it has long been known that HIV-1 down-regulates CD4 cell surface expression $[3,4]$, the loss of CD4 is not complete and the HIV-infection does not reduce CD4 mRNA levels [5]. Thus, a method based on quantitating CD4 and CD8 mRNA could provide a means of assessing immune status without requiring repetitive and large blood draws, and could be exquisitely sensitive. This method may also be useful in assessing the immune status of patients retrospectively from archived or frozen samples. QC-RT-PCR, and related methodologies, however, did not prove useful as substitutes for assessment of CD4 and CD8 cell numbers in HIV-infected persons.

\section{Results}

Samples were acquired from Special Hematology, Louisiana State University Medical Center, after exempt status was obtained from Tulane Institutional Review Board. The relationship between CD4 and CD8 cell number by flow cytometry, and the amount of mRNA as quantitated by QC-RT-PCR, was determined. Flow cytometry was performed as previously described [6] along with white blood cell and differential counts, including percent lymphocytes, in order to determine numerical values. Intact mRNA was successfully extracted from as little as $400 \mu \mathrm{l}$ of whole blood, comparable amounts to that obtained from infants via heelstick. This mRNA was used to quantify the amount of CD4, CD8, as well as GAPDH, mRNA that is being transcribed in Tlymphocytes within the blood. The corrected quantity of CD4 and CD8 mRNA as determined by QC-RT-PCR and the corresponding CD4 and CD8 counts of that patient as determined by flow cytometry are depicted in Table 1. The patients' HIV status, if known, is also shown. The patients with unknown status all have inverted CD4:CD8 cell ratios and are therefore likely to be HIV infected (the majority of the samples sent for flow cytometry are HIV-positive). The relationship between the mRNA and cell number for CD4 and CD8 are depicted (Fig. 1A, 1B). The correlation coefficients are $-0.2 \mathrm{~S}$ and 0.13 respectively.

\section{Discussion}

Our results indicate that there is no correlation between CD4 and CD8 mRNA levels and numbers of cells expressing these proteins on their surface. The formation of CD4gp160 complexes in intracellular compartments may contribute to cell surface CD4 down-modulation during HIV-
1 structural protein expression [4]. These and other mechanisms may explain the lack of correlation between message and surface expression in HIV-positive individuals. HIV infection may also interfere with the translation or surface expression of CD8, although it is not used as a viral receptor. Whatever the mechanism, no correlation between CD4 and CD8 cell counts and mRNA levels of CD4 and CD 8 could be determined by QC-RT-PCR. There was also no correlation between CD4 and CD8 mRNA levels and the number of cells expressing these proteins on their surface. Given the magnitude of the variations observed by QC-RT-PCR it is unlikely that other methods to quantitate these mRNAs, e.g. northern blotting or real-time PCR, would reveal a correlation either.

\section{Conclusions}

QC-RT-PCR and related techniques such as real-time PCR are not useful as substitutes for assessment of CD4 and CD8 cell status in HIV-infection by flow cytometry.

\section{Methods QC-RT-PCR}

The strategy for development of competitor templates for quantitative-competitive RT-PCR (QC-RT-PCR) was similar to that of Lipman and coworkers [7]. Oligonucleotide primers (Clontech, Palo Alto, CA) were chosen that span introns of CD4 and CD8 genes in order to avoid amplification of cellular DNA contaminating RNA preparations. Products are generated from cDNA and deletional mutants are constructed by restriction endonuclease digestion and religation. The deletional mutants were then subcloned using the TA cloning vector pCR2.1 (Invitrogen, Carlsbad, CA), and sequenced for confirmation. The method used to generate a competitor for CD8 was slightly different than previously reported methods. The wild type PCR product was inserted into the TA cloning vector before digesting with BbsI, an enzyme with no recognition sites inside the vector and only one site in the insert. The linearized plasmid was gel purified, the free ends of the plasmid were then shortened using Bal31 nuclease. The ends were filled using the Klenow fragment of DNA Polymerase, and then religated. The competitor template for glyceraldehyde phosphate dehydrogenase (GAPDH), used to control the amount of RNA in each extraction, have already been constructed by Lipman et al., (1994), and were kindly provided by Dr. Martha Pavlakis, Harvard Medical School, Boston, MA. The primer sequences are: Sense 5'GGTGAAGGTCGGAGTCAACG3', Antisense 5'CAAGTTGTCATGGATGACC3'.

All plasmids were consequently purified and serially diluted. Known concentrations of the competitor cDNA was amplified in the same reaction tube as unknown amounts of sample derived RT-cDNA. This CDNA was obtained as follows. Total RNA is extracted from $400 \mu \mathrm{l}$ to $1 \mathrm{ml}$ of 


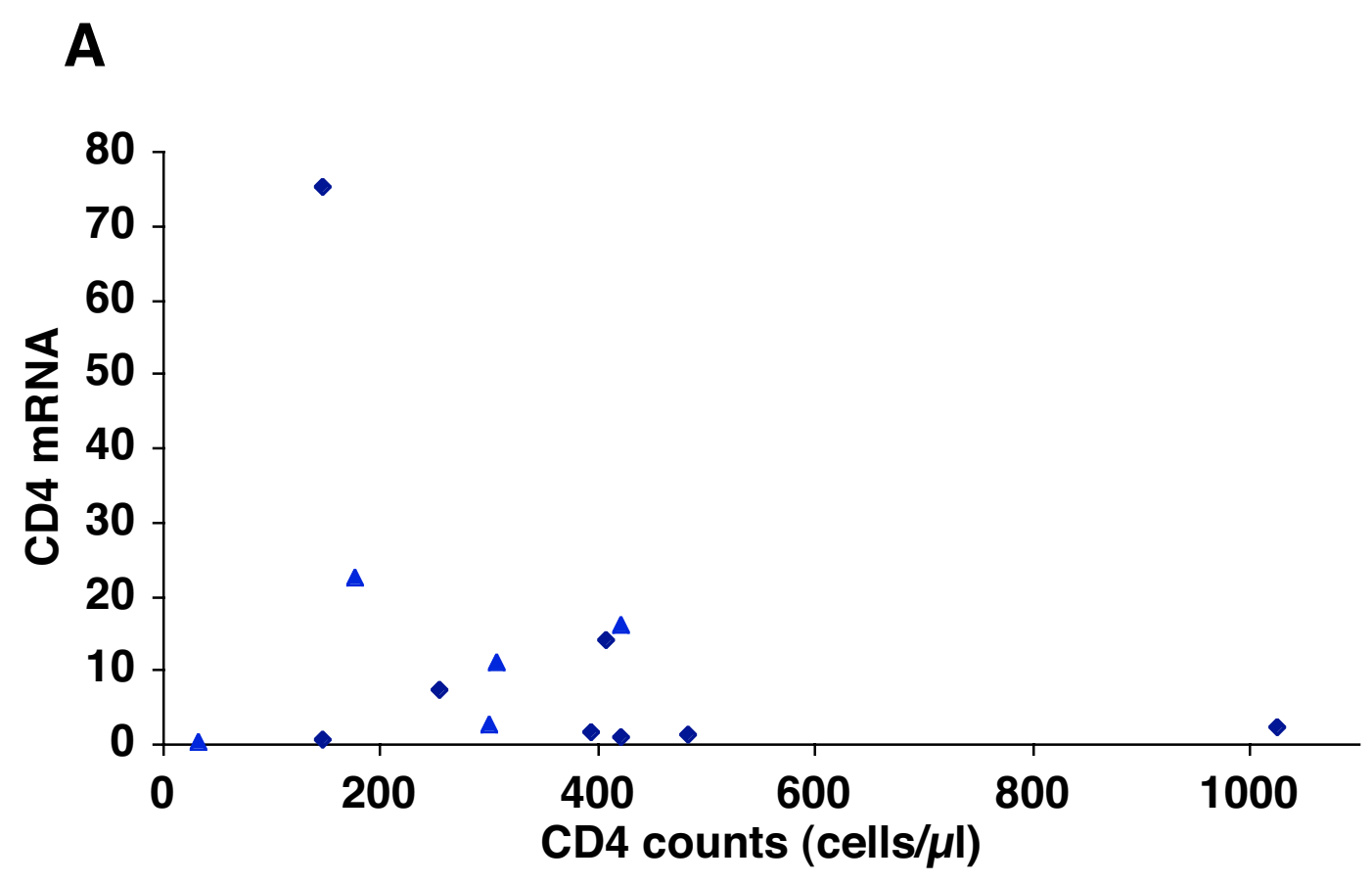

B

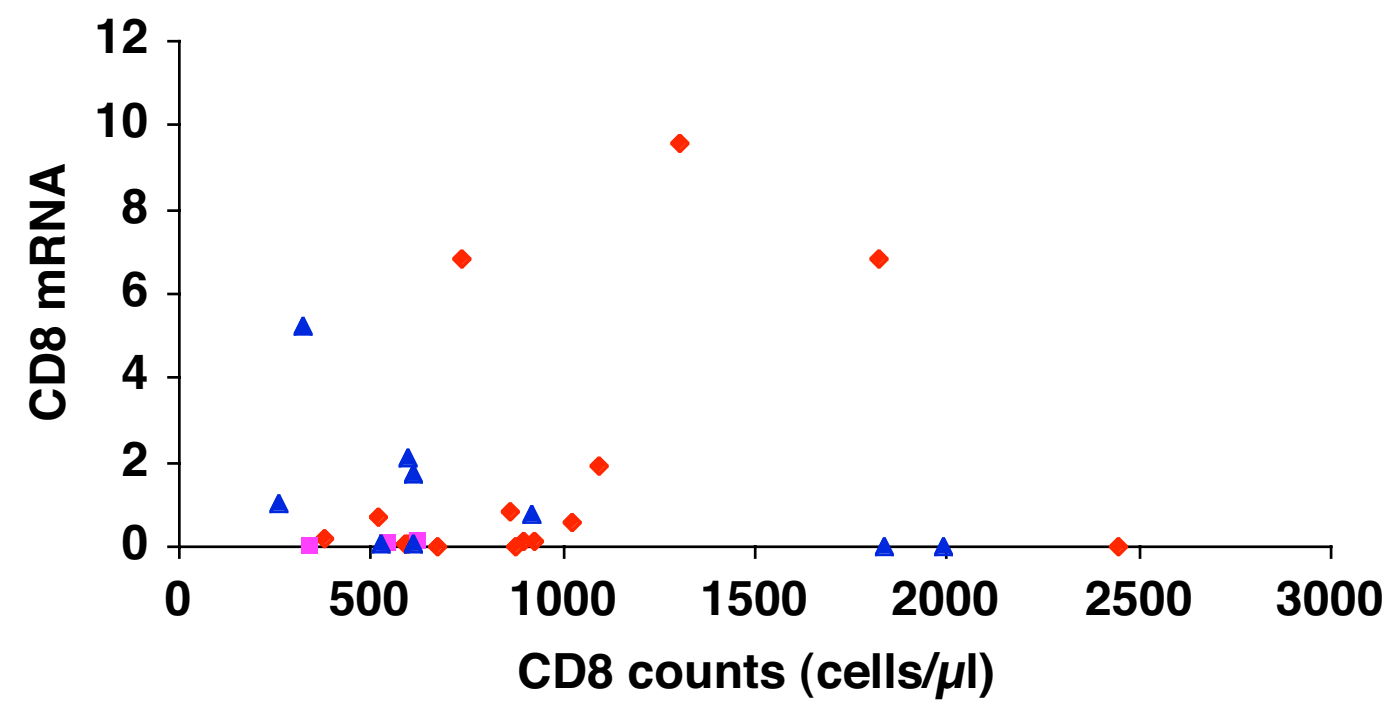

Figure I

The relationship between cell counts and the quantity of mRNA as determined by QC-RT-PCR. (A) CD4, and (B) CD8. The HIV status of each sample is depicted. represents HIV positive status, $\mathbf{a}$ represents HIV negative status, and $\boldsymbol{A}$ $*$

reepresents unknown status. 
whole blood using a similar method to Zhang and Yunis [8]. First strand cDNA is synthesized using oligo dT primers and Maloney murine leukemia virus reverse transcriptase (Promega, Madison, WI), diluted 1 to 3, then 3 $\mu \mathrm{l}$ is used as template in a $25 \mu \mathrm{l}$ PCR. The remainder of the reactions were made up by $5 \mu \mathrm{l}$ PCR Buffer (Gibco BRL, Grand Island, NY), $0.25 \mu \mathrm{g}$ of each primer, $6 \mathrm{mM} \mathrm{MgC12}$ in each CD4 reaction and $4 \mathrm{mM} \mathrm{MgC12}$ for CD8 reactions, $2 \mathrm{mM}$ total dNTP's, and $0.5 \mathrm{U}$ of Taq Polymerase. For CD4 and CD8 reaction conditions were : $94^{\circ}$ for 3 mins, then 33 cycles of $94^{\circ}$ for 45 secs, $55^{\circ}$ for 45 secs, and $72^{\circ}$ for 2 mins on a Perkin Elmer Thermocycler. 33 cycles was chosen as this was the largest number still within the linear range of the PCR (data not shown). In each assay we performed at least six different reactions for each sample using increasing amounts of competitor DNA. The amounts of sample were quantitated by extrapolating across at least three reactions in which approximately equal amounts of sample and competitor products were produced.

The PCR products are run on a 1.5\% agarose gel. Quantity of sample derived mRNA can be determined when the intensity of its PCR band is equal to that of the competitor's upon co-amplification. Staining with ethidium bromide can be quantitative provided that digital imaging is employed [9]. The standard curve plots the log cDNA/competitor band intensity (as determined by analysis of PICT files with NIH image) on the x-axis versus the log of incremental dilutions of competitor DNA on the y-axis. Solving for the antilog of $\mathrm{x}$ when $\mathrm{y}=0$ will give the concentration of unknown amount of DNA - that of CD4, CD8 or GAPDH. The success of the RNA extraction and reverse transcription is determined by quantification of GAPDH mRNA by QC-RT-PCR. Each value for quantity of CD4 or CD8 mRNA was standardized according to the amount of GAPDH mRNA in the sample.

\section{Authors' contributions}

Heather Jaspan conceived of the study, performed all the molecular analyses, and wrote the manuscript. Richard Gaumer provided patient samples and performed flow cytometry analyses. Robert Garry supervised the study and contributed to the writing of the mansccript.

\section{Acknowledgements}

Supported by NIH Grant Number F30 MHI I 33 I and the Keck Foundation.

\section{References}

I. Piatak M Jr, Saag MS, Yang LC, dark SJ, Kappes JC, Luk KC, Hahn BH, Shaw GM and Lifson JD High levels of HIV-I in plasma during all stages of infection determined by competitive PCR. Science 1993, 259(5 I02): 1749-1754

2. McKinney RE Jr and Wilfert CM Lymphocyte subsets in children younger than 2 years old: normal values in a population at risk for human immunodeficiency virus infection and diagnostic and prognostic application to infected children. Pediatr Infect Dis J 1992, I I (8):639-644
3. Stevenson $M$, Zhang $\mathrm{XH}$ and Volsky DJ Downregulation of cell surface molecules during noncytopathic infection of $T$ cells with human immunodeficiency virus. J Virol 1987, 6 I ( I 2):374I3748

4. Crise $B$ and Rose JK Human immunodeficiency virus type I glycoprotein precursor retains a CD4-p56Ick complex in the endoplasmic reticulum. J Virol I992, 66(4):2296-230 I

5. Geleziunas R, Bour S, Boulerice F, Hiscott J and Wainberg MA Diminution of CD4 surface protein but not CD4 messenger RNA levels in monocytic cells infected by HIV-I. AIDS I99I, 5(I):2933

6. Gaumer HR Optimizing the comparison of two and four color flow cytometric immunophenotyping. Cytometry 1998, Supplement 9:109

7. Lipman ML, Stevens AC and Strom TB Heightened Intragraft CTL gene expression in acutely rejecting renal allografts. J Immunol 1994, I52(10):5 |20-5|27

8. Zhang $Y$ and Yunis JJ Improved blood RNA extraction microtechnique for RT-PCR. Biotechniques 1995, I 8(5):788-792

9. Shubsda MF, Goodisman J and Dabrowiak JC Quantitation of ethidium-stained closed circular DNA in agarose gels. J Biochem Biophys Methods 1997, 34(I):73-79
Publish with Bio Med Central and every scientist can read your work free of charge

"BioMed Central will be the most significant development for disseminating the results of biomedical research in our lifetime. " Sir Paul Nurse, Cancer Research UK

Your research papers will be:

- available free of charge to the entire biomedical community

- peer reviewed and published immediately upon acceptance

- cited in PubMed and archived on PubMed Central

- yours - you keep the copyright

Submit your manuscript here:

http://www.biomedcentral.com/info/publishing_adv.asp
BioMedcentral 